\title{
A infraestrutura rodoviária na urbanização do território paulista: as escalas de integração da cadeia produtiva, 1913-1944
}

TAVARES, Jefferson Cristiano

\section{Resumo}

O objetivo é apresentar como a infraestrutura rodoviária atuou na urbanização do território paulista a partir da necessidade de integração da cadeia produtiva industrial, na primeira metade do século XX. Nossos objetos de estudos são os planos rodoviários pioneiros que foram implantados ou influenciaram o desenho da maIha rodoviária paulista, propostos entre 1913 e 1944, especificamente o Plano de Viação de São Paulo, o Plano Nacional Rodoviário e o Plano da Rodovia Panamericana, que abrangem as escalas regional, nacional e internacional. A partir desses planos é possível identificar a predominância de um modelo morfológico radial que articulou o território consolidando a estrutura de polos urbanos já existentes. De um modo geral, demonstraremos como a repercussão desses planos definiu áreas mais bem equipadas e, portanto, propícias à urbanização. E como essa urbanização esteve condicionada pela necessidade de integrar a cadeia produtiva industrial, tendo em vista a função estratégica do Estado de São Paulo de principal produtor e mercado consumidor do país. Concluiremos, portanto, que as escolhas de implantação dos planos rodoviários - na escala regional, nacional e internacional; dos seus principais eixos; e da valorização dos centros urbanos - repercutiram na formação do território submetendo o processo de urbanização paulista à lógica produtivista industrial.

Palavras-chave: Infraestrutura. Rodovias. Urbanização. Estado de São Paulo. Planos Rodoviários. Cadeia Produtiva.

\begin{abstract}
:
The goal of this paper is to assess how road infrastructure influenced the urbanization of São Paulo state, based on the need to integrate the industrial production chain, during the first half of the twentieth century. The objects of study are the first road plans which were implemented or influenced highway designs in São Paulo between 1913 and 1944, particularly Plano de Viação de São Paulo, Plano Nacional Rodoviário, and Plano da Rodovia Panamericana, at regional, national, and international scales. These plans make it possible to identify the prevalence of a radial morphology model that articulated the territory by consolidating the structure of existing urban centers. Overall, this paper shows how the impact of these plans defined better equipped areas which were, therefore, conducive to urbanization, as well as how urbanization was conditioned by the need to integrate the industrial production chain, given São Paulo's strategic role of top producer and consumer market in the country. We conclude that the decisions to implement road plans - at regional, national, and international level - and their main axes, in addition to the importance of urban centers, affected the formation of the territory, subjecting the urbanization process in São Paulo to a productivist industrial logic.
\end{abstract}

Keywords: Infrastructure. Roads. Urbanization. São Paulo State. Highway Plans. Industrial Production Chain. 


\section{Introdução}

O desenho das rodovias sobre o território paulista representa uma importante estratégia para a integração da atividade industrial paulista que, no início do século $X X$, firmava-se como principal atividade econômica do Estado. A passagem do predomínio de uma economia agrícola para uma economia industrial, entre as décadas de 1920 e 1940 no Estado de São Paulo, provocou uma reestruturação territorial a fim de integrar as atividades da cadeia produtiva. Essa transformação territorial vinculada às novas atividades econômicas exigiu a implantação de novas formas de transporte terrestre, tendo em vista a substituição das ferrovias pelas estradas.

O apoio à abertura de estradas foi pioneiramente incentivado por Washington Luis, que se utilizou de todos os artifícios políticos nas suas gestões como secretário de estado (1906-1912), deputado (1912-1913), prefeito (1914-1919), governador (1920-1924) e presidente da república (19261930) para promover o modelo rodoviário como principal sistema de transportes.

Além do apoio de Washington Luis, houve uma organização institucional que mobilizou incentivos privados e públicos para o desenvolvimento das rodovias. Congressos paulistas, realizados entre 1917 e 1923, sistematizaram as principais diretrizes técnicas e divulgaram as qualidades do novo sistema de transporte automotor (SICILIANO, 1967, p. 29). E em 1921 foi criada, pela Lei 1.835-C, a Inspetoria de Estradas de Rodagem, na época subordinada à Diretoria de Obras Públicas e atrelada à Secretaria da Agricultura (D’ALESSANDRO, 1967, p. 27). O Estado de São Paulo foi, assim, precursor na organização institucional e influenciou a organização federal. Paralelamente a essa organização institucional, decorreram soluções para o território através de três principais planos e suas repercussões.

\section{O Plano de Viação de São Paulo, 1913: o Modelo Radial}

A organização administrativa refletiu as transformações econômicas e reverteu os recursos públicos para a abertura de estradas e construção de rodovias. O marco desse processo é o Plano de Viação para São Paulo (1913), que, embora seja o segundo plano rodoviário do Estado de São Paulo, foi o embrião da estrutura rodoviária paulista. O primeiro Plano de Viação de Rodagem foi elaborado na vigência da presidência (da província) de Campos Salles em 1896 (D'ALESSANDRO, 1967, p. 24). E o segundo Plano de Viação foi elaborado em 1913 por
Clodomiro Pereira da Silva, engenheiro e consultor técnico da Secretaria de Agricultura do Estado de São Paulo. Foi entregue na vigência do governo de Francisco de Paula Rodrigues Alves, sendo Washington Luis prefeito da Capital. Nesse plano ficaram estabelecidas as principais diretrizes, que, passado um século, permanecem na malha rodoviária paulista.

A estrutura do território paulista está baseada nas rodovias radiais. São elas as principais ordenadoras da produtividade econômica e responsáveis pela consolidação da urbanização paulista. Para estabelecer essa base, o Plano partiu da importância dos elementos geográficos e do processo de urbanização como fundamentais para a organização das formas de transporte (SECRETARIA DA AGRICULTURA..., 1913, p. 20). A opção por linhas radiais justificou-se pela posição da capital, no limite leste do Estado; pela geografia, principalmente a hidrografia, quase paralela, descendo a oeste da capital; pelo processo de urbanização em curso e pela presença já consolidada das vias férreas que ligavam os principais núcleos do interior à capital.

\footnotetext{
Penso que para satisfazer às primeiras necessidades, bastaria crear boas estradas de rodagem entre as príncipes cidades do Estado, particularmente da Capital aos pontos vizinhos mais proximos: a Santos, Jundiahy, Campinas, Sorocaba, Mogi das Cruzes, etc. [...]. (SECRETARIA DA AGRICULTURA..., 1913, p. 34).
}

A ausência das vias transversais é constatada pelo autor e justificada pela grande escala de produção e escoamento para poucos pontos concentrados, ou seja, pela valorização das atividades produtivas. A questão produtiva predominou no desenho dessas vias, configurando a estrutura territorial sobre a qual foi concebido o plano de viação:

\footnotetext{
Estas serão estradas de rodagem commerciaes, mas que servirão necessariamente a interesse de ordem administrativa e política; mas o interesse predominantemente actual será de ordem econômica. (SECRETARIA DA AGRICULTURA..., , 1913, p. 48, grifo no original).
}

As principais rodovias, hierarquicamente denominadas de "estradas especiais", constituíram-se, por fim, como os principais troncos radiais:

Das estradas especiaes, entendo que o Governo deve promover, desde já, o estabelecimento das seguintes:

$1^{\circ}$. de São Paulo a Taubaté 


\author{
$2^{\circ}$. de São Paulo a Santos \\ $3^{\circ}$. de São Paulo a Campinas, Piracicaba e \\ Ribeirão Preto \\ $4^{\circ}$. de São Paulo a Avaré, por Sorocaba. \\ (SECRETARIA DA AGRICULTURA..., 1913, p. 50).
}

Dessa forma, os quatro troncos radiais previstos deram origem às quatro principais rodovias que cruzam o Estado de São Paulo, atualmente: a Dutra; a Anchieta; a Anhanguera; e a Regis Bittencourt. Seu traçado privilegiou as relações econômicas, ao buscar interligar a capital às fronteiras regionais.

O desenho desse traçado que se definiu em 1913 foi responsável pela estruturação paulista, influenciando e sendo influenciada pela urbanização do seu território através da valorização de algumas cidades em desenvolvimento e através da constituição de regiões econômicas que gozaram de intensa produtividade ligada à concentração industrial na capital. De certo, as maiores influências podem ser representadas por três, das quatro, rodovias: a ligação com o Rio de Janeiro, por constituir-se no principal parque industrial do país; a ligação com Santos, pela importância da exportação e importação; e a entrada para o interior via Campinas, regiões historicamente com maior índice de urbanização e desenvolvimento.

Figura 1: Estradas interestaduais inauguradas até 1926.

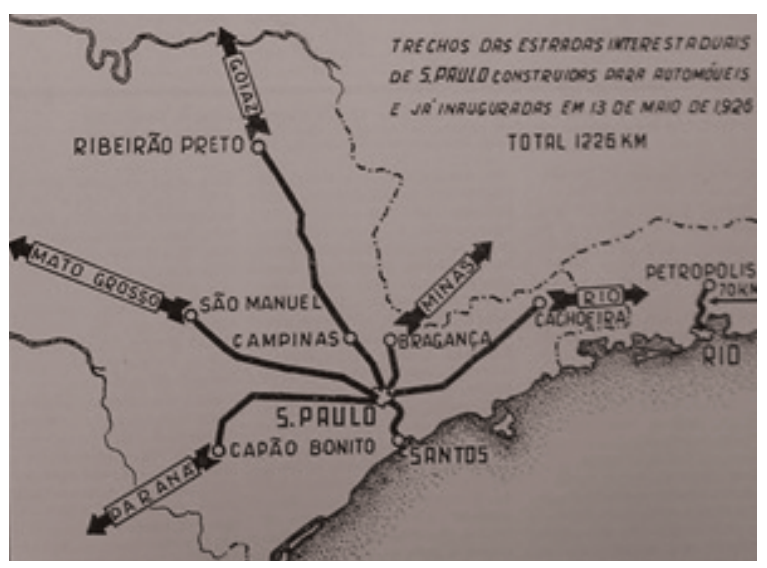

Fonte: Revista DER, n. 67, 1952.

\section{São Paulo no Circuito Internacional da Atividade Industrial: a Rodovia Panamericana, Década de 1920 à Década de 1940}

Na década seguinte ao Plano de Viação, nos anos 1920, o contexto internacional foi marcado pela crise da bolsa de Nova York, que afetou a economia mundial. Nos Estados Unidos, a crise econômica, bem como a experiência recente da Guerra Mundial direcionaram as decisões da economia internacional pela proteção militar e autossuficiência americana. A opção por uma política de importação de matéria-prima e exportação de bens manufaturados foi a garantia da constituição de um mercado forte e protegido das instabilidades do período bélico. Para essa concretização, contudo, a rodovia tornou-se numa importante estratégia de integração do mercado internacional produtivo pelo atendimento às necessidades da América Latina com os produtos norte-americanos. A partir de então a política norte-americana divulgou um plano rodoviário internacional, cujo resultado deveria ser a constituição de uma rodovia que ligasse as três Américas e proporcionasse a ampliação do mercado consumidor.

Tecnicamente, sucederam-se duas iniciativas de destaque nos congressos internacionais e que foram relevantes para o desenho da respectiva rodovia. $\mathrm{Na}$ VI Conferência Internacional Americana, realizada em Havana em 1928, foram envolvidas várias organizações (a União PanAmericana, o Congresso Pan-Americano de Estradas de Rodagem - na sua segunda edição -, a Confederação Pan-Americana de Educação Rodoviária, o Instituto Pan-Americano e os governos a elas vinculados). Ficou estabelecido:

\footnotetext{
Aprovar plenamente a iniciativa de construir uma estrada internacional americana, e recomendar, a todos os membros da União Pan-Americana, que cooperem em todo o possível à pronta realização do dito projeto. (PENTEADO, 1943, p. 384)
}

A proposta era ligar todas as capitais latino-americanas através de um sistema linear que aproveitasse as rodovias já existentes e construísse as que fossem necessárias, como foi o caso das obras nas rodovias da América Central. $\mathrm{O}$ objetivo foi estabelecer um trajeto internacional que integrasse todos os principais polos consumidores aos Estados Unidos e os articulasse com possíveis fornecedores de matéria-prima.

No II Congresso Internacional de Estradas de Rodagem, realizado no Rio de Janeiro em 1929, houve a representação brasileira de Timoteo Penteado, que atestou as ligações propostas e sugeriu alterações, sobretudo nas ligações da capital federal, Rio de Janeiro, às capitais de outros países:

Tivemos em consideração que, do ponto de vista brasileiro, o problema não comporta uma só estrada, mas diversas estradas internacionais pan-americanas, porque, em síntese, a Rodovia 
Pan-americana se reduz à ligação, entre elas, de todas as capitais dos países americanos por ótimas estradas de rodagem. (PENTEADO, 1943, p. 384, grifo nosso).

A proposta original ligava Rio de Janeiro-São Paulo-Porto Alegre-Montevideo-Buenos Aires numa única linha. Apenas a capital Buenos Aires tinha ramificações a outros países, e o Rio de Janeiro constituía-se como ponto final do trajeto. Penteado propôs outras estradas pan-americanas que ligassem Rio de Janeiro a Assuncion e La Paz, passando por São Paulo, estendendo as ramificações da rodovia e tornando o Rio de Janeiro um polo concentrador e São Paulo um importante entreposto. A proposta de Penteado buscou articular as duas principais capitais regionais brasileiras ao sistema internacional proposto.

Décadas depois, nos anos 1940 no período da II Guerra Mundial, houve um reforço norte-americano em concluir rapidamente o percurso total e garantir, entre os objetivos econômicos (pouco expostos, mas muito evidentes na primeira fase), mais um recurso de defesa que unisse os países aliados aos Estados Unidos. Foi na década de 1940 que surgiram as justificativas ideológicas para reafirmar o empreendimento e garantir que a sua finalização - cerca de $87 \%$ (!) do traçado já estava operando - ocorresse, sobretudo a partir dos financiamentos norte-americanos.

Através do Banco de Importação e Exportação norte-americano, os Estados Unidos disponibilizaram empréstimos de aproximadamente US\$ $78,000,000.00$ aos países da América Central e México (principalmente) e América do Sul, num período inferior a vinte anos. Os argumentos utilizados nessa década confirmaram a finalidade da rodovia de integrar o mercado norte-americano.

Nosso país (EUA) também depende dos produtos da América Central e do Sul para fortalecer sua economia de tempo de paz. [...] Com a melhoria dos meios de transporte e comunicação, esses produtos terão seu emprego acrescido nas indústrias dos Estados Unidos e seu comércio aumentado nos demais países americanos. A rodovia panamericana será um fator importante na consecução desse resultado. (ROADS AND STREETS, 1943, p. 54).

Ao todo, seis programas de melhorias vinculadas ao transporte terrestre continental garantiriam a melhoria do desenvolvimento econômico norte-americano.
1. A melhoria dos transportes no interior dos vários países e entre eles e os Estados Unidos:

[...] As exportações norte-americanas desses produtos [produtos de massa, como trigo, arroz ou feijão escassos nos países da América Central] são insignificantes, mas a melhoria dos transportes e o aumento resultante da capacidade de consumo abririam mercados adicionais aos produtos norte-americanos.

2. Desenvolvimento de novas regiões e novos recursos naturais, com o aumento do consumo das importações americanas:

[...] Daí resultaria um notável aumento do movimento turístico para os Estados Unidos e da importação americana por esses portos.

3. Melhor emprego e manutenção das estruturas econômicas:

A construção rodoviária e novas empresas asseguradas por melhor transporte garantirão emprego no atual período de dificuldades econômicas. [...].

4. Maior intercâmbio turístico aumentaria grandemente, dos Estados Unidos, na direção sul, [...] e que o mesmo movimento desses pontos para a nossa terra teria também notável desenvolvimento. [...]

5. Melhor mercado para nossos automóveis, peças, equipamento de garagem, etc.:

O tráfego da rodovia através do México e da América Central até a zona do Canal resultaria na ampliação do mercado para os automóveis e caminhões norte-americanos. [...]

6. Valor defensivo. (ROADS AND STREETS, 1943, p. 54, 55, 56).

O que resulta desses esforços é o predomínio territorial do mercado norte-americano. A rodovia pan-americana cumpriria seu papel de articular os núcleos mais produtivos de toda a América de forma hierarquizada a um sistema produtivo centralizado nos Estados Unidos. O Estado de São Paulo, especificamente sua capital, São Paulo, protagonizou um trecho dessa passagem definida pelo tronco principal da rodovia, e se tornou parte desse mercado articulado ao Rio de Janeiro. As futuras Rodovias Dutra e Regis Bittencourt, por sua vez, integraram-se ao sistema produtivo internacional, reforçando o padrão radial que se consolidou no território nacional e, em especial, no Estado de São Paulo. Nesse processo, alicerçou-se a estrutura 
radial (prevista pelo Plano de 1913) como principal desenho para o transporte paulista integrado ao mercado regional e internacional.

Figura 2: Proposta da Rodovia Panamericana.

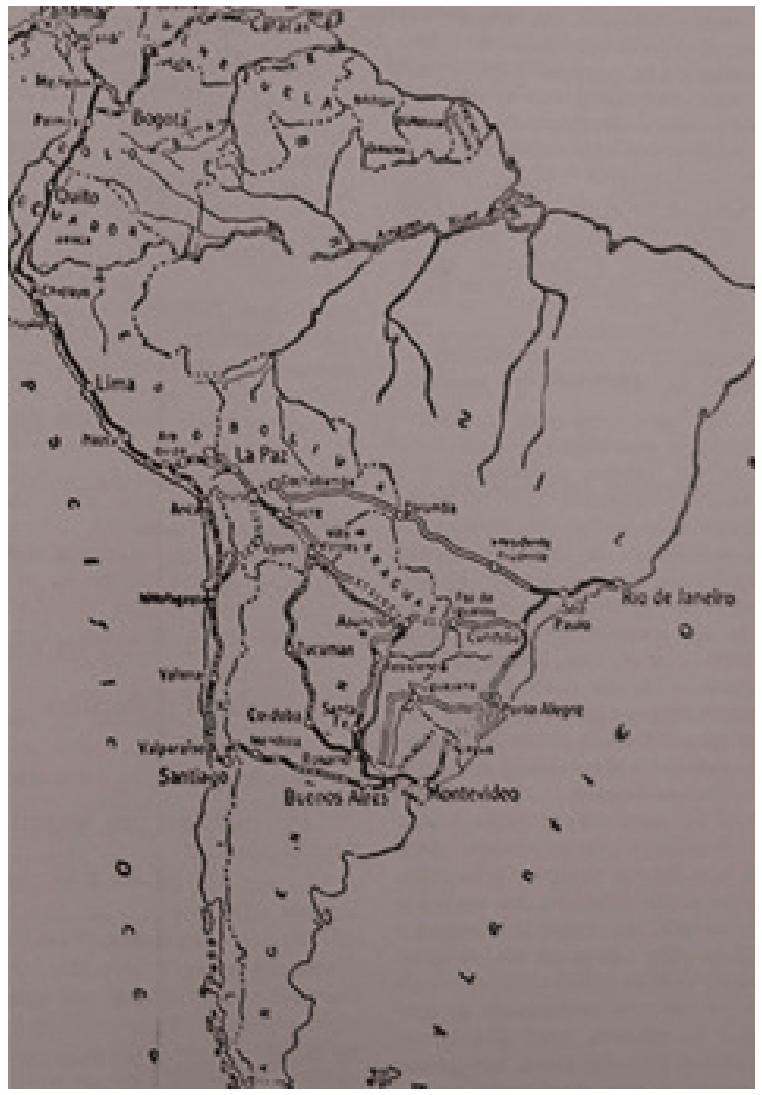

Fonte: Revista DER, n . 59, 1950

\section{Plano Nacional Rodoviário, 1944: o Atendimento aos Centros Econômicos Produtivos Consolidados}

Diretamente vinculado ao desenvolvimento econômico regional do país, o Plano Nacional Rodoviário foi proposto com a finalidade de equipar o território nacional evidenciando o viés econômico da concepção e da implantação da infraestrutura de transportes terrestres.

Podemos afirmar que, dentre os esforços empreendidos pelo poder público, o Plano Rodoviário Nacional, de 1944, foi o ápice dos esforços de integração do mercado consumidor por meio da circulação de produtos no período de industrialização nacional. Definido pelo Decreto n. 15.093 de 20 de março de 1944, foi elaborado por Comissão específica presidida por Yedo Fiuza, diretor do DNER.

O partido adotado do Plano gerou um padrão cartesiano de rodovias sobre o território nacional. A orientação pelos eixos N-S e E-W definiu a estrutura de uma grelha ortogonal que se sobrepôs à geografia do território nacional, ajustando-se às regiões urbanizadas e polarizadas. Essa estrutura estabeleceu-se por pontos de partida ou de chegada que estavam vinculados às capitais estaduais ou às cidades mais importantes das principais regiões. O desenho em grelha gerou poucos cruzamentos, e essa escassez valorizou essas próprias cidades, pois elas se transformaram nos entroncamentos e nos entrepostos das principais rodovias. Essas cidades, que podem ser consideradas nós do sistema quadricular, ganharam importância desproporcional, por corresponderem não apenas aos centros urbanos já consolidados, mas também a elementos estruturantes valorizados pelo novo sistema logístico.

Dessa grelha, poucas rodovias avançaram para o interior do país, sobretudo nos seus quadrantes norte e centro-oeste, comprovando a permanência de vias radiais originadas pelos centros. A malha, por assim dizer, é muito mais escassa nessas porções e muito adensada no Sudeste e no Nordeste pelas vias estruturais e pelas suas ramificações privilegiando os principais centros urbanos. Podemos perceber um sistema concentrado entre Salvador e Fortaleza e entre São Paulo e Rio de Janeiro, com extensões pontuais a outros centros regionais mais distantes. Considerando que o principal parque industrial do país já estava consolidado no eixo Rio de Janeiro-Belo Horizonte-São Paulo e que a maior concentração populacional alongava-se historicamente pela costa brasileira, o Plano Nacional correspondeu à intenção de integrar produtor e mercado consumidor a partir de um sistema logístico eficiente. É notório o objetivo em atender à produtividade das regiões já consolidadas sem o cuidado em desenvolver as regiões com poucas oportunidades.

São Paulo, capital, foi privilegiada pela sua posição no mapa econômico nacional, disputando com o Rio de Janeiro a maior produtividade industrial. Assim o Plano Nacional transformou-a em importante articulador regional/territorial, ligando São Paulo diretamente ao Rio de Janeiro, a Belo Horizonte, a Curitiba, a Corumbá e a Goiânia, como já previa o Plano de Viação do Estado (1913). Mas, não só, pois o plano integrou-se ao contexto internacional ao atender aos princípios da Rodovia Panamericana, pois o considerou na definição do principal eixo RioSão Paulo.

[...] aproveitando essa transversal, é indicada, como trecho brasileiro da Rodovia

Panamericana, a diretriz, que tem os seguintes 
pontos principais de passagem: Rio de Janeiro

- São Paulo - Campinas - Rio Claro -

Araraquara - Rio Preto - Presidente Vargas

- Campo Grande - Corumbá. (DNER, 1944, p.

10).

Dessa forma, o Plano Nacional inseriu o mercado nacional, em especial o carioca e o paulista, no sistema produtivo internacional. Possibilitou à capital paulista a função estratégica de entreposto regional na rota Rio de JaneiroMontevideo-Buenos Aires-La Paz, adotando as premissas da Rodovia Panamericana (DNER, 1944, p. 8)

Nesse plano, São Paulo estava atravessado por três das cinco principais rodovias que estruturaram o sistema proposto (duas - Rodovia I e Rodovia IV -, no sentido N-S; e uma - Rodovia $X V I I-$, no sentido E-W). As outras duas rodovias (XXIV e XXV), com caráter regional, estabeleceram a triangulação RJ-MG-SP e, embora com curtas distâncias, supriram os principais centros produtivos, possibilitando o desenvolvimento e a produtividade articulados ao restante do país. A concentração logística correspondeu, claramente, à concentração de riquezas desses três estados.

Algumas particularidades são essenciais para compreender a importância desse sistema para o Estado de São Paulo. A Rodovia I - Getulio Vargas tem importância por ligar o Norte ao Sul do país beirando a costa e, portanto, consolidando importantes eixos ferroviários ou viários já existentes. Para o Estado de São Paulo, é a consolidação de um importante corredor de desenvolvimento definidor do processo de urbanização concentrada. É a rodovia cujo traçado corresponde ao da Rodovia Dutra e ao da Rodovia Regis Bitencourtt.

A Rodovia IV - Transbrasiliana poderia ter criado um importante entreposto econômico na cidade de Rio Preto e outro em Ourinhos, por estabelecer, na primeira cidade, o cruzamento dos eixos $\mathrm{N}-\mathrm{S} / \mathrm{E}-\mathrm{W}$ do país (cruzamento da IV $\mathrm{x}$ XVII) e na segunda um entreposto intermediário entre os estados de São Paulo e Paraná. Não atendia, contudo, aos principais centros e, consequentemente, não foi implantada.

A Rodovia XVII Transversal do Estado de São Paulo, no Plano Nacional, é a rodovia de maior importância regional para o território paulista, porque estabelecia um eixo comercial integrando o litoral ao interior do país. Foi a rodovia cujo traçado correspondeu ao sistema composto pelas rodovias Anchieta/Imigrantes, Anhanguera/ Bandeirantes e Washington Luis. Foi o único eixo longitudinal do Estado; passava por três capitais estaduais (São Paulo, Campo Grande e Corumbá) e integrava a diretriz Pan-Americana de estabelecer a ligação entre o Rio de Janeiro e La Paz (Bolívia). Seu traçado respeitou os divisores d'água, ao seguir a linha férrea existente e se opôs à lógica secular do desenvolvimento concentrado no litoral. Foi, portanto, o eixo que, ao contrariar a regra de desenvolvimento da costa leste, proporcionaria desenvolvimento e concentração de riqueza no sentido oeste do país, em especial do Estado de São Paulo.

A Rodovia XXIV, cujo traçado correspondeu à Fernão Dias, ligou duas importantes capitais e estabeleceu um corredor produtivo no interior de São Paulo, sendo fundamental para o circuito turístico e sua consolidação como região paulista, conhecida por Sul de Minas. Embora de curta distância, em relação às principais rodovias nacionais, estabeleceu uma ligação histórica, superando a topografia acidentada das serras, principalmente da Serra da Cantareira e da Mantiqueira.

Por fim, a Rodovia XXV Ligação ResendeAraraquara também integrava as diretrizes da Rodovia Pan-Americana de ligação com o interior e vislumbrava um importante centro econômico, Araraquara, a ser integrado à produção industrial de Resende. Sua importância seria comprovada pela desconcentração do desenvolvimento, espraiando os recursos sem deixar de articular os dois principais estados do país. Possivelmente foi esse o motivo de não ter sido construída.

A notoriedade dos eixos $\mathrm{N}-\mathrm{S}$ efetivou-se com as ligações de São Paulo com Rio de Janeiro, Belo Horizonte e Curitiba. São Paulo, capital, foi evidentemente a cidade com maior importância nessa análise regional. Mas, nesse contexto, cabe destacar a importância dada às cidades, do interior, Ourinhos, Araraquara e Rio Preto, por serem nós rodoviários de um sistema regional e nacional. Ourinhos, por cumprir o papel de entrada e saída para o Paraná; Araraquara, por garantir a continuidade de sua importância histórica de "boca do sertão" e estabelecer a ligação entre São Paulo-Rio de Janeiro; e Rio Preto, com maior importância, por estar no cruzamento dos dois principais eixos $\mathrm{N}-\mathrm{S} \times \mathrm{E}-\mathrm{W}$ do país. Nota-se que as rodovias concretizadas, ao menos parcialmente em território paulista, garantiram a consolidação daqueles que seriam os principais espaços com alto padrão de desenvolvimento econômico, reforçando significativamente a implantação das rodovias no processo de urbanização territorial, ao ser capaz de influenciar o 
desenvolvimento de algumas regiões privilegiadas.

Figura 3: Plano Nacional Rodoviário.

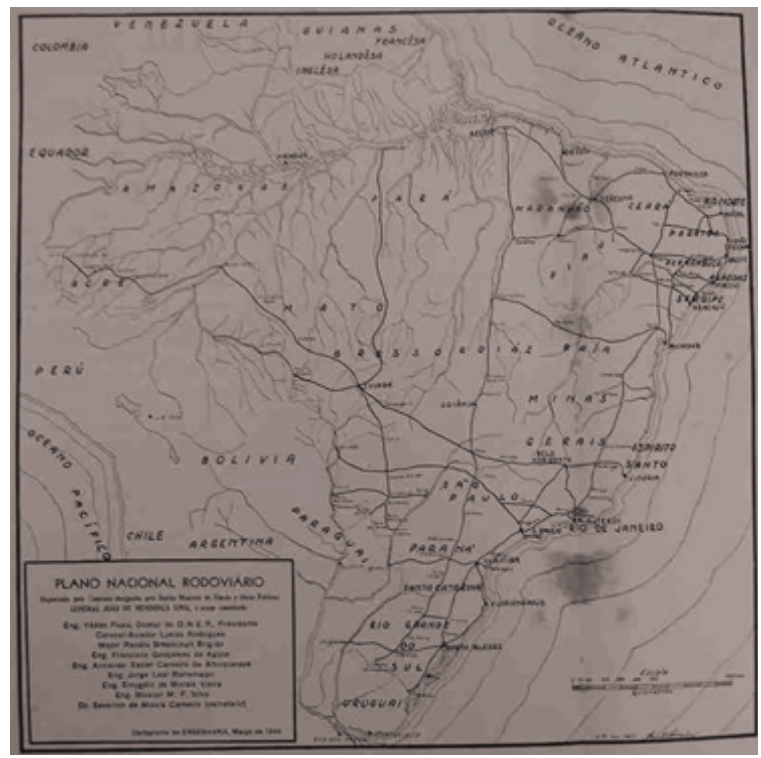

Fonte: Revista Engenharia Mackenzie, n. 85, 1944

\section{Considerações Finais}

Toda infraestrutura concebida na escala regional tem, na sua origem, o estímulo à produtividade. Ao contrário dos equipamentos de abrangência local, aqueles que se destinam à escala regional são propostos com a finalidade de incentivarem as atividades produtivas, sobretudo as industriais, se considerarmos o Estado de São Paulo ao longo do século XX. Nessas condições e nesse contexto, podemos considerar que, pelas evidências, o modelo produtivo predominante esteve baseado na cadeia produtiva fordista, que considerava um sistema de fornecedores e produtores satélites de diversos níveis, organizados hierarquicamente e direcionados a um polo concentrador, a capital paulista. Na leitura de Allen Scott (1998, p. 65), a integração da cadeia produtiva é um importante condicionador das relações de urbanização:

\footnotetext{
Fordist industrialization between about 1920 and 1965 was based more than anything else on propulsive growth pole sectors marked by powerful internal economies of scale. In its archetypal embodiment it consisted of industries like cars, machinery, domestic appliances, etc. which, together with their associated constellations of direct and indirect input suppliers, generated massive urban and regional concentrations of capital and labor as exemplified by the classic North American manufacturing metropolis.
}

A nosso ver, esse modelo direcionou a urbanização territorial do Estado de São Paulo, porque a concepção rodoviária, ao atender ao aumento da produtividade interna, baseou-se nos princípios da cadeia produtiva fordista e se tornou, assim, a principal responsável pela articulação entre o polo produtivo central e os demais polos intermediários, responsáveis pelo fornecimento de matérias-primas e manufaturados, constituídos como satélites fornecedores. Essa ação valorizou algumas cidades ao longo dessas rodovias e reforçou o processo de urbanização pelos investimentos e facilidades de acessos.

A urbanização do Estado de São Paulo pautou-se, entre outras condicionantes, pela organização territorial entre as cidades e a infraestrutura de circulação. E a infraestrutura de circulação, predominantemente a rodoviária, foi concebida para garantir o desenvolvimento econômico das regiões paulistas a partir da integração da cadeia produtiva industrial. Na ideia de Allen Scott (1998, p. 78), um exemplo de espaço econômico baseado na produtividade industrial:

\footnotetext{
One of these is represented by pyramid-like industrial complexes where large lead plants (often possessing a wide scope of internalized production activities) sit at the top of transactional hierarchies of smaller input suppliers, service providers, and subcontractors. This polarized organizational form is typical of the car or aerospace industries.
}

A relação entre as principais cidades estaduais e as rodovias que a atendem demonstra que a grande maioria delas está distribuída ao longo das principais rotas produtivas - eixos propostos e consolidados entre 1913 e 1944 pelos planos estadual, nacional e pan-americano (São Paulo, Santos, Taubaté, Campinas, Piracicaba, Araraquara, São José do Rio Preto, Ourinhos, Sorocaba e Avaré, diretamente abordadas pelos planos rodoviários; bem como outras cidades que se localizam ao longo desses eixos, como São Bernardo do Campo, São José dos Campos, São Carlos, Ribeirão Preto, Guarulhos, Jundiaí etc.). Assim, o modelo rodoviário que se implantou no Estado de São Paulo, concebido nas suas diferentes escalas a partir da década de 1910, reproduziu, no espaço, as relações da cadeia produtiva fordista e consolidou uma estrutura territorial hierarquizada, polarizada e concentrada, que pode ser identificada pela predominância da capital paulista e pela relação das demais cidades a ela. 


\section{Referências}

CURY, A B. Da Organização de um Plano Rodoviário. Revista Engenharia Mackenzie, v. XV, n. 85, p. 13-20, 1944.

D'ALESSANDRO, A. Retrospecto do rodoviarismo paulista. Revista DER, v. 28, n. 103-104, p. 22-28, 1967.

DNER - Departamento Nacional de Estradas de Rodagem. Plano Rodoviário Nacional. Rio de Janeiro: [s.n.], 1944.

GALVÃO, J. T. O Brasil e o Plano Rodoviário Transcontinental. Revista DER, v. XVII, n. 59, p. 47-50, 1950.

NETTO, A. R. A origem da "rodovia" no Brasil. Revista DER, v. XVII, n. 67, p. 41-47, 1952.

PENTEADO, T. A Rodovia Pan-Americana. Engenharia, v. I, n. 11, p. 383-384, 1943.

ROADS AND STREETS. A linha vital do Novo Mundo. A Rodovia, n. 45, p. 53-57, 1943.

SECRETARIA DA AGRICULTURA, COMMERCIO E OBRAS PUBLICAS. Plano de Viação: Relatorio apresentado ao Dr. Secretario da Agricultura, pelo Consultor Technico da Secretaria, Engenheiro Clodomiro Pereira da Silva. São Paulo: Tip. Levi, 1913.

SCOTT, A. J. Regions and the world economy: the coming shape of global production, competition, and political order. New York: Oxford University Press Inc., 1998.

SICILIANO, L.de B. Rodoviarismo histórico. Revista DER, v. 28, n. 103-104, p. 29-30, 1967. 